\title{
Application of response surface methodology to assess the combined effect of operation variables on high-pressure coal gasification for $\mathrm{H}_{2}$-rich gas production
}

\author{
J. Fermoso, M.V. Gil, B. Arias, M.G. Plaza, C. Pevida, J.J. Pis, F. Rubiera* \\ Instituto Nacional del Carbón, CSIC. Apartado 73. 33080 Oviedo. Spain
}

\begin{abstract}
Coal gasification was performed by means of a high-pressure fixed bed gasifier fitted with a solids feeding system in continuous mode, using oxygen and steam as gasifying agents. A face centered central composite design (FCCCD) based on response surface methodology (RSM), was used to assess the combined effects of the operation variables (temperature, oxygen and steam concentrations) on high-pressure coal gasification. The response variables studied were: $\mathrm{H}_{2}, \mathrm{CO}$ and syngas production, $\mathrm{H}_{2} / \mathrm{CO}$ ratio, cold gas efficiency $(\eta)$ and carbon conversion $(X)$. The study was carried out at temperatures of 900,950 and $1000^{\circ} \mathrm{C}$, using oxygen concentrations of 5, 10 and 15 vol.\%, and steam concentrations of 25,40 and $55 \mathrm{vol} . \%$. The gasification temperature was found to be the most influential variable, with high temperatures leading to an increase in all the response variables studied. An increase in the oxygen content of the gasifying agent led to a decrease in $\mathrm{H}_{2}$ and $\mathrm{CO}$ production, and cold gas efficiency, whilst carbon conversion was favoured. An increase in steam concentration, on the other hand, favoured the production of $\mathrm{H}_{2}$ and syngas production, whereas $\mathrm{CO}$ production underwent a reduction; cold gas efficiency and carbon conversion were observed to increase. Response surface methodology (RSM) revealed the effects of interaction between the operation variables, which would not have been identified by the traditional "one-factor-at-a-time" method. The models developed successfully fitted the experimental results for all the response variables studied.
\end{abstract}

Keywords: hydrogen production; high-pressure gasification; coal; response surface methodology

\section{Introduction}

The clean and efficient use of coal by means of gasification is considered to be a promising alternative for ensuring the continued demand for this fuel in the energy 
markets. This technology is characterised by its high versatility, the possibility of using a wide range of fuels (coal, biomass, petroleum coke, etc.), and the variety of applications open to the obtained product. The syngas produced can be used to generate electricity (IGCC), chemical feedstocks, hydrogen, etc., depending on the demand of the market. Energy systems based on hydrogen are considered a promising scenario in the long term. The advantages of hydrogen energy include its low environmental impact and its future application in fuel cell technology to produce electricity [1]. Currently, 98 $\%$ of the hydrogen produced comes from fossil fuels, mainly from natural gas reforming (approx. $50 \%$ ) [2]. However, due to the uncertainty of natural gas supply and the fluctuations in its prices, it seems that, in the medium term, systems based on coal gasification may offer a possible alternative. Coal gasification is a well established technology for producing syngas $\left(\mathrm{CO}+\mathrm{H}_{2}\right)$, where hydrogen production can be increased by means of the water-gas shift reaction (WGS), $\mathrm{CO}+\mathrm{H}_{2} \mathrm{O} \leftrightarrow \mathrm{CO}_{2}+\mathrm{H}_{2}$. With this technology, a highly concentrated stream of hydrogen can be generated provided that $\mathrm{CO}_{2}$ capture stage is also undertaken. Some studies have shown that electricity generation based on the combination of hydrogen fuel cells and $\mathrm{CO}_{2}$ capture are less costly compared to post-combustion systems $[3,4]$.

Response surface methodology (RSM) is a useful statistical technique which has been applied in research in complex variable processes [5,6]. This technique involves the design of experiments and multiple regression analysis as tools to assess the effects of two or more independent variables on dependent variables [7]. Its main advantage is that it requires fewer experimental runs to generate the information necessary for a statistically acceptable result. RSM helps researchers to build models, evaluate the effects of several factors and establish the optimum conditions for the desired responses. The analysis of variance (ANOVA) provides statistical results upon which diagnostic checking tests can be based to enable researchers to evaluate the suitability of the models [8].

In this work, high-pressure coal gasification in a fixed bed reactor fitted with a solids feeding system designed to ensure the steady production of $\mathrm{H}_{2}$-rich gas has been studied by means of response surface methodology. The general objectives of the study were: (i) to assess the combined effects of the operation variables (temperature, oxygen and steam concentrations) on high-pressure coal gasification, and (ii) to determine the 
optimum values, within the experimental range of each operation variable, in order to maximize the response variables depending on the gasification applications. To achieve these aims, RSM was employed.

\section{Experimental}

In this work, a bituminous Spanish coal (PT) was used. This coal together with petcoke is currently used as feedstock at the Elcogas IGCC power plant, which is located in Puertollano (Spain) [9]. The sample was ground and sieved to obtain a fraction with a particle size of $75-150 \mu \mathrm{m}$. The proximate and ultimate analyses and the high heating value of the sample are presented in Table 1.

The experimental device used for the gasification tests has been described in detail in a previous work [10]. Briefly, it consists of a stainless steel tubular reactor with a porous plate, which is able to work at a maximum pressure of 20 atm at $1000^{\circ} \mathrm{C}$. Fuel particles are fed continuously into the system from a pressurized hopper, which ensures a steady gas production.

The gasification tests were carried out isothermally at a constant pressure of $15 \mathrm{~atm}$, using as gasifying agents a mixture of steam and oxygen, carried in an inert flow of $\mathrm{N}_{2}$, at a total flow rate of $200 \mathrm{Ncm}^{3} \mathrm{~min}^{-1}$. The coal mass flow rate used for these tests was $5 \mathrm{~g} \mathrm{~h}^{-1}$. The composition of the dried gases $\left(\mathrm{H}_{2}, \mathrm{O}_{2}, \mathrm{~N}_{2}, \mathrm{CO}, \mathrm{CH}_{4}\right.$ and $\left.\mathrm{CO}_{2}\right)$ was analysed on line, using a dual channel micro-GC Varian CP-4900. The amount of gas generated during the experiments was calculated from a nitrogen balance, since the amount of nitrogen fed in and the composition of the nitrogen evolved are known.

\section{Methods}

\subsection{Response variables}

One of the principal advantages of high-pressure coal gasification technology is that the syngas produced can be used for a variety of applications. For this reason, the process can be employed to optimize different response variables. Thus, in the case of hydrogen generation, the most important variable would be the proportion of $\mathrm{H}_{2}$ present in the produced gas. However, the production of $\mathrm{CO}$ and total syngas $\left(\mathrm{H}_{2}+\mathrm{CO}\right)$ production would also have to be taken into account, since the $\mathrm{CO}$ is transformed into $\mathrm{CO}_{2}$ and $\mathrm{H}_{2}$ by means of the WGS. On the other hand, if the aim were the synthesis of chemicals 
(e.g. methanol, or liquid fuels by means of the Fischer-Tropsch process) the $\mathrm{H}_{2} / \mathrm{CO}$ ratio would be an important parameter to study. Another possible application is electricity generation in a combined cycle, in which case, the main variable to optimise would be cold gas efficiency, $\eta$. Finally, the carbon conversion obtained during the process, $X$, is a response variable that always needs to be maximized, since this variable shows the amount of solid fuel that is transformed into gas.

In this work the response variables studied were: $\mathrm{H}_{2}, \mathrm{CO}$ and syngas production (expressed in mol kg${ }^{-1}$ sample, daf), $\mathrm{H}_{2} / \mathrm{CO}$ ratio, cold gas efficiency (\%), and carbon conversion (\%). Cold gas efficiency, $\eta$, was defined as the ratio between the energy content of the gas and the energy contained in the solid fuel. Carbon conversion, $X$, was defined as the total amount of carbon contained in the gas produced $\left(\mathrm{CH}_{4}, \mathrm{CO}\right.$ and $\left.\mathrm{CO}_{2}\right)$ with respect to the total amount of carbon contained in the sample fed in.

\subsection{Experimental design}

The independent variables selected for the study of high-pressure coal gasification and their respective levels were as follows: reaction temperature $\left(900,950\right.$ and $\left.1000{ }^{\circ} \mathrm{C}\right)$, oxygen concentration (5, 10 and 15 vol.\%) and steam concentration $(25,40$ and 55 vol.\%). The possible effects of interaction between the operation variables were studied employing a suitable experimental design that would allow the experimental results to be fitted to a polynomial response surface model. Amongst a number of central composite designs, a face centered central composite design (FCCCD) was adopted for this study. This involved 20 experiments (Table 2$)$, including eight factorial points $\left(2^{3}\right.$ full factorial design), six axial points corresponding to the face centres of the cube portion of the design, and six replicates at the centre of the design. The latter provide information about the interior of the experimental region, and allow the curvature and experimental error to be evaluated [5]. Prior to the application of the factorial experimental design, the operation variables were coded in order to facilitate calculations, and increase the fit of the coefficients estimation. Once the variables have been coded all the coefficients will have the same units and can be compared with one another [11]. Table 2 shows the coded (in parentheses) and the decoded independent variables $\left(\mathrm{T}, \% \mathrm{O}_{2}\right.$ and $\left.\% \mathrm{H}_{2} \mathrm{O}\right)$ together with the experimental values for the response variables $\left(\mathrm{H}_{2}, \mathrm{CO}, \mathrm{H}_{2}+\mathrm{CO}, \mathrm{H}_{2} / \mathrm{CO}, \eta\right.$ and $\left.X\right)$. 


\subsection{Statistical analysis}

Response surface methodology (RSM) is an empirical modelling approach for determining the relationship between various operation variables and response variables. It provides a sequential experimentation strategy for building and optimizing an empirical model. Thus, RSM is a collection of mathematical and statistical procedures that are useful for the modelling and analysis of problems in which the response is affected by operation variables. The objective is to optimize these variables taking into account the desired value of the response function [7]. By means of experimental design and applying regression analysis, a desired response to several independent variables can be modelled. In RSM, the quantitative form of the relationship between the response and the independent variables can be represented as

$y=f\left(x_{1}, x_{2}, x_{3} \ldots x_{n}\right) \pm \varepsilon$

where $y$ is the response variable, $f$ is the response function (or response surface), $x_{i}$ are the independent variables, and $\varepsilon$ is the fitting error.

The response function has the appearance of a surface, and the possibility of establishing a suitable approximation of $f$ to the experimental results will determine whether the application of RSM is successful or not. The necessary data for building the response models are generally collected by the design of experiments. In this study, the experimental data were collected from FCCCD and the approximation of $f$ was attempted by using a second-order polynomial regression model (quadratic model), generated by the statistical software package SPSS Statistics 17.0. The second-order polynomial equation employed was the following:

$y=\beta_{0}+\sum_{i=1}^{3} \beta_{i} x_{i}+\sum_{i=1}^{3} \beta_{i i} x_{i}^{2}+\sum_{i=1}^{2} \sum_{j=i+1}^{3} \beta_{i j} x_{i} x_{j}+\varepsilon$

where $y$ is the response variable, $x_{i}$ is the $i$ th independent variable, $\beta_{0}$ is the intercept, $\beta_{i}$ are the linear coefficients, $\beta_{i i}$ are the quadratic coefficients for the variable $i$, and $\beta_{i j}$ are the linear model coefficients for the interaction between the variables $i$ and $j$. The response was fitted to the independent variables by means of multiple regression analysis. The quality of the fitted polynomial model was expressed by the coefficient of determination $\mathrm{R}^{2}$, which represents the proportion of variability in a set of data that is accounted for a statistical model. However, $\mathrm{R}^{2}$ increases as the number of variables in the model increases. It is therefore more appropriate to use $\mathrm{Adj}-\mathrm{R}^{2}$, which penalizes the 
statistic $\mathrm{R}^{2}$ as extra variables are included in the model. In fact, Adj- $\mathrm{R}^{2}$ decreases if unnecessary terms are added.

In order to test the statistical significance of the fit of the quadratic model to the experimental data, tests for the significance of the regression model, the individual model coefficients and lack-of-fit were performed. This statistical evaluation of the models for all of the response variables was performed by Analysis of Variance (ANOVA) using SPSS Statistics 17.0. The results of these tests together with the coded coefficients of the proposed quadratic models are summarized in Tables 3 and 4 . The ANOVA tests showed which of the proposed models are statistically significant. In this case, all of the models were shown to be significant, given that they are able to explain a $95 \%$ of the variability in the response. The terms in the models were evaluated by the $p$ value at a confidence level of $95 \%$. Terms that were not statistically significant ( $p$-value $>0.05)$ were eliminated from the models without damaging the model fitting. The lack of fit was also calculated, and was found to be not significant for all the response surface models at a $95 \%$ confidence level.

Once the proposed models were considered significant, the coefficients were decoded in order to relate the models to the real operation variables as it is shown in Table 5.

To visualize the combined effects of two factors on any response, three-dimensional plots, showing the response surfaces, and their respective contour plots were generated, using SigmaPlot 8.0, for each of the fitted models as a function of two independent variables, while the other variable was set at the central value of its range $\left(\mathrm{T}: 950{ }^{\circ} \mathrm{C}\right.$, $\% \mathrm{O}_{2}$ and $\% \mathrm{H}_{2} \mathrm{O}: 10$ and 40 vol.\%, respectively).

\section{Results and discussion}

\section{$\mathrm{H}_{2}$ production}

The regression equation for hydrogen production (Table 5) shows that this depends largely on the three individual dependent variables and on the interaction between temperature and steam concentration. The latter could be due to the fact that hydrogen is mainly produced by steam gasification reactions, which are extremely endothermic. Figure 1 shows the response surfaces (1) and the contour plots (2) for hydrogen production, with the temperature (a) and the oxygen concentration (b) set at $950{ }^{\circ} \mathrm{C}$ and 10 vol.\%, respectively. The response surfaces for the other levels of temperature (900 
and $1000^{\circ} \mathrm{C}$ ) and oxygen concentrations (5 and 15 vol.\%) within the experimental range are not shown because they are parallel to those presented in this work. It can be observed that hydrogen production is favoured with the increase in temperature and steam concentration and with the decrease in oxygen in the gasifying agent, in agreement with the results obtained in a previous work [10]. The most outstanding feature of this model is shown in Figures 1 (b1) and 1 (b2), where the curvature of the response surface and the contour plot isolines, respectively, reveal the effect of interaction between the temperature and the steam concentration. This interaction demonstrates that, when gasification is carried out at low temperatures, a higher steam concentration is necessary in the gasifying agent to obtain the same amount of hydrogen production as that achieved at elevated temperatures. Thus, if the aim of the process is to maximize $\mathrm{H}_{2}$ production, the optimum values for the operation variables within this experimental region would be: $1000{ }^{\circ} \mathrm{C}, 5$ vol. $\% \mathrm{O}_{2}$ and 55 vol. $\% \mathrm{H}_{2} \mathrm{O}$.

\section{CO production}

The regression equation for $\mathrm{CO}$ production (Table 5) shows that carbon monoxide production depends significantly on the three individual dependent variables, and on the interactions between temperature and oxygen concentration, and between temperature and steam concentration. Figure 2 shows the combined effects of temperature and gasifying agent concentrations $\left(\% \mathrm{O}_{2}\right.$ and $\left.\% \mathrm{H}_{2} \mathrm{O}\right)$ on $\mathrm{CO}$ production through the curvature of the response surfaces (1) and the contour plots (2), with the steam (a) and the oxygen concentrations (b) set at 40 and 10 vol.\%, respectively. In Figures 2 (a1) and 2 (a2) it can be observed that an increase in the oxygen concentration in the gasifying agent produces a decrease in $\mathrm{CO}$ production, this decrease being especially noticeable at high temperatures. Likewise, Figures 2 (b1) and 2 (b2) show the same behaviour for the temperature and steam concentration. Thus, to achieve maximum $\mathrm{CO}$ production the operation variables need to be of: $1000{ }^{\circ} \mathrm{C}, 5$ vol.\% $\mathrm{O}_{2}$ and 25 vol. $\% \mathrm{H}_{2} \mathrm{O}$.

\section{$\mathrm{H}_{2}+\mathrm{CO}$ production}

The regression equation for $\mathrm{H}_{2}+\mathrm{CO}$ production (Table 5) shows that syngas production only depends significantly on the three individual dependent variables This indicates that the positive effect resulting from the interaction between temperature and steam 
concentration on hydrogen production is counteracted by the negative effect that this interaction has on $\mathrm{CO}$ formation, leading to the cancellation of this combined effect on syngas production. Figure 3 shows the response surfaces (1) and the contour plots (2) for syngas production with the temperature (a) and oxygen concentration (b) set at 950 ${ }^{\circ} \mathrm{C}$ and 10 vol.\%, respectively. In these plots it can be observed that syngas production is favoured by an increase in the reaction temperature, a decrease in the oxygen concentration and an increase in the steam content of the gasifying agent, although $\mathrm{CO}$ production is impeded by the steam. This behaviour shows that hydrogen production is more strongly affected by the interaction between temperature and steam concentration than CO. Thus, to maximize syngas production the optimum values for the operation variables would need to be: $1000{ }^{\circ} \mathrm{C}, 5$ vol. $\% \mathrm{O}_{2}$ and 55 vol. $\% \mathrm{H}_{2} \mathrm{O}$.

\section{$\mathrm{H}_{2} / \mathrm{CO}$ ratio}

The regression equation for the $\mathrm{H}_{2} / \mathrm{CO}$ ratio (Table 5) shows that this response depends significantly on the three individual dependent variables, and on the interactions between temperature and oxygen concentration, and between oxygen and steam concentration. The interactions between the operation variables not only produced a certain curvature on the response surfaces and the contour plots, as occurred with $\mathrm{H}_{2}$ and $\mathrm{CO}$ production; but also the surfaces generated were not parallel, causing a change in the response variable as a function of the level of the fixed variable (temperature, oxygen or steam concentration) when the other dependent variables change. Consequently, in this case the response surfaces and the contour plots at the three levels of the fixed dependent variable have been plotted as a function of the other two variables.

Figure 4 shows the response surfaces (a) and the contour plots (b1, b2 and b3) for the $\mathrm{H}_{2} / \mathrm{CO}$ ratio as a function of the gasifying agent components, with the temperature set at three levels 900,950 and $1000^{\circ} \mathrm{C}$, respectively. It can be observed in these figures that, independently of the level of the other variables, the $\mathrm{H}_{2} / \mathrm{CO}$ ratio increases as the reaction temperature decreases and the steam concentration increases. These general tendencies reflect those of a previous work [10]. Furthermore, in the previous study it was observed that, at a temperature of $950{ }^{\circ} \mathrm{C}$, the $\mathrm{H}_{2} / \mathrm{CO}$ ratio decreased as the oxygen concentration in the gasifying agent increased. In the present study, additional 
information has been obtained by means of response surface methodology. From plots (b1), (b2) and (b3) in Figure 4, it can be observed that at low values of steam concentration, the $\mathrm{H}_{2} / \mathrm{CO}$ ratio falls when the oxygen content in the gasifying agent is increased at any temperature, this reduction being more pronounced the lower the temperature. However, at high values of steam concentration, the trend observed in $\mathrm{H}_{2} / \mathrm{CO}$ ratio is strongly dependent on the temperature. Thus, at a temperature of $950{ }^{\circ} \mathrm{C}$, the $\mathrm{H}_{2} / \mathrm{CO}$ ratio hardly changes when the oxygen concentration is increased. Nevertheless, at $900{ }^{\circ} \mathrm{C}$, this ratio falls when the oxygen concentration increases, whilst at $1000{ }^{\circ} \mathrm{C}$, there is a clear rise in the $\mathrm{H}_{2} / \mathrm{CO}$ ratio with the increase in oxygen content. In Figure 5 the response surfaces (a) and contour plots (b1, b2 and b3) for the $\mathrm{H}_{2} / \mathrm{CO}$ ratio are plotted as a function of temperature and steam concentration, the oxygen concentration being set at three levels: 5, 10 and 15 vol.\%, respectively. These figures show a rise in the $\mathrm{H}_{2} / \mathrm{CO}$ ratio when the steam concentration is increased at any temperature and at any oxygen concentration, this increase being noticeably higher for higher oxygen concentrations. On the other hand, regardless of the gasifying agent concentrations, the $\mathrm{H}_{2} / \mathrm{CO}$ ratio decreases when the reaction temperature increases, especially at low oxygen concentrations. The most outstanding characteristic in Figure 5 is at high values of the steam concentration where the response surfaces intersect. Here the tendencies change with the temperature increase. Thus, at low temperatures the $\mathrm{H}_{2} / \mathrm{CO}$ ratio increases as the oxygen concentration decreases independently of the steam concentration, whilst at high temperatures the opposite occurs. In contrast, at low steam concentration values, the $\mathrm{H}_{2} / \mathrm{CO}$ ratio always increases as the oxygen concentration decreases; and the lower the temperature, the greater the rise.

Finally, Figure 6 shows the response surfaces (a) and contour plots (b1, b2 and b3) for the $\mathrm{H}_{2} / \mathrm{CO}$ ratio as a function of temperature and oxygen concentration, with the steam concentration being set at three levels 25,40 and 55 vol.\%, respectively. This figure shows that the $\mathrm{H}_{2} / \mathrm{CO}$ ratio is enhanced by an increase in steam concentration at any oxygen concentration and reaction temperature, probably due to the fact that the secondary steam gasification reaction is favoured with the result that $\mathrm{H}_{2}$ and $\mathrm{CO}_{2}$ production increases, while $\mathrm{CO}$ production decreases. It can also be observed that at low temperatures, $900{ }^{\circ} \mathrm{C}$, the $\mathrm{H}_{2} / \mathrm{CO}$ ratio diminishes as the oxygen content in the gasifying agent increases. However, at high temperatures $\left(1000{ }^{\circ} \mathrm{C}\right)$ the trend followed by the 
$\mathrm{H}_{2} / \mathrm{CO}$ ratio depends on the steam concentration. Thus, at low values of steam concentration this ratio falls, whilst high steam values favour this ratio as the oxygen content increases.

\section{Cold gas efficiency}

The regression equation for cold gas efficiency, $\eta$, (Table 5) shows that this response variable depends significantly on the three individual dependent variables and on the interaction between oxygen and steam concentrations. In Figure 7 the response surfaces (1) and the contour plots (2) for cold gas efficiency are plotted with the temperature (a) and the oxygen concentration (b) set at $950{ }^{\circ} \mathrm{C}$ and 10 vol.\%, respectively. It can be observed that cold gas efficiency is enhanced by a rise in the reaction temperature. These results agree with the studies of other authors who employed different types of gasifiers such as pressurized spouted bed and fluidised bed reactors [12-16]. However, an increase in the oxygen content in the gasifying atmosphere leads to a decrease in this parameter, as oxidation reactions are favoured to the detriment of the gasification reactions [17,18]. Figures 7 (a1) and 7 (a2) clearly show the interaction effects of the gasifying agents on cold gas efficiency. Thus, an increase in steam concentration leads to higher values of cold gas efficiency. If the steam concentration continued to rise (over 55 vol.\%), cold gas efficiency would reach a maximum after which it would start to decrease $[10,19,20]$. However, within the experimental range, the increase in cold gas efficiency is higher at lower values of oxygen content in the gasifying atmosphere. High values of steam concentration in the reactive atmosphere result in a reduction of cold gas efficiency as the oxygen concentration increases.

\section{Carbon conversion}

The regression equation for the carbon conversion (Table 5) shows that the effects of interaction between the operation variables are mixed, and only the three individual independent variables are statistically significant. Figure 8 presents the response surfaces (1) and the contour plots (2) for carbon conversion with the temperature (a) and the oxygen concentration (b) set at $950{ }^{\circ} \mathrm{C}$ and $10 \mathrm{vol} \%$, respectively. In this figure it can be observed that an increase in each of the independent variables has a positive effect on carbon conversion, the order of influence being: $\mathrm{T}>\% \mathrm{O}_{2}>\% \mathrm{H}_{2} \mathrm{O}$. These 
trends were expected, as high temperatures and high oxygen concentrations enhance the oxidation and breakdown of the molecular bonds in coal, leading to a greater conversion of solid carbon to gaseous molecules. An increase in the reaction temperature by $100{ }^{\circ} \mathrm{C}$ led to a rise in carbon conversion of between 11.5-33.5\% depending on the gasifying agent composition. For all the range of steam concentrations studied in this work, an increase in carbon conversion was obtained.

\section{Validation of the models}

Additional experiments, within the experimental range of the study, were carried out in order to check the robustness of the proposed models for the response variables studied by comparing the predicted values with those obtained experimentally under several experimental conditions. Figure 9 shows the predicted values versus those experimentally obtained in the additional experiments and those used for the experimental design, there being a good fitting, even for the additional experiments.

\section{Conclusions}

Extensive statistical analyses of the combined effects of gasification operation variables (temperature, oxygen and steam concentrations) on different process parameters such as $\mathrm{H}_{2}, \mathrm{CO}$ and syngas production, $\mathrm{H}_{2} / \mathrm{CO}$ ratio, cold gas efficiency $(\eta)$ and carbon conversion $(X)$ were performed by means of response surface methodology (RSM) in a series of gasification experiments. These experiments were carried out using a highpressure fixed bed gasifier fitted with a solids feeding system in continuous mode. The appearance of some effects of interaction among the operation variables provided valuable information about the process that would not have come to light, using the traditional "one-factor-at-a-time" method. Gasification temperature was found to be the most influential variable: there was an increase in all the response variables when the temperature was increased. An increase in the oxygen content in the gasifying agent resulted in a decrease in $\mathrm{H}_{2}$ and $\mathrm{CO}$ production, and in turn in cold gas efficiency, whereas carbon conversion was favoured. An increase in steam concentration was observed to favour $\mathrm{H}_{2}$ and syngas production, whereas $\mathrm{CO}$ production decreased. Cold gas efficiency and carbon conversion also increased. The proposed models fit reasonably well the experimental results for all the response variables studied in this 
work. The Adj- $\mathrm{R}^{2}$ calculated for all the models exceeded 0.95, showing good correlations. Additional experiments, within the experimental range, were performed in order to evaluate the robustness of these models with very successful results.

\section{Acknowledgements}

This work was carried out with financial support from the Spanish CDTI (Project CENIT PiIBE). J.F. acknowledges funding from the PCTI Asturias, and M.G.P acknowledges funding from the CSIC I3P Program, co-financed by the European Social Fund.

\section{References}

[1] A. Midilli, M. Ay, I. Dincer, M.A. Rosen, On hydrogen and hydrogen energy strategies I: Current status and needs, Renew. Sustain. Energy Rev. 9 (2005) 255271.

[2] S. Dunn, Hydrogen futures: toward a sustainable energy system, Int. J. Hydrogen Energy, 27 (2002) 235-264.

[3] K. Damen, M. van Troost, A. Faaij, W. Turkenburg, A comparison of electricity and hydrogen production systems with $\mathrm{CO}_{2}$ capture and storage. Part A: Review and selection of promising conversion and capture technologies, Prog. Energy Combust. Sci. 32 (2006) 215-246.

[4] K. Damen, M. van Troost, A. Faaij, W. Turkenburg, A comparison of electricity and hydrogen production systems with $\mathrm{CO}_{2}$ capture and storage. Part B: Chain analysis of promising CCS options, Prog. Energy Combust. Sci. 33 (2007) 576605.

[5] G.-T. Jeong, H.-S. Yang, D.-H. Park, Optimization of transesterification of animal fat ester using response surface methodology, Biores. Tech. 100 (2009) 25-30.

[6] K.-T. Chiang, C.-C. Chou, N.-M. Liu, Application of response surface methodology in describing the thermal performances of a pin-fin heat sink, Int. J. Thermal Sci. 48 (2009) 1196-1205.

[7] R.H. Myers, D.H. Montgomery, Response Surface Methodology, John Wiley \& Sons, USA, 1995.

[8] S. Ghafari, H.A. Aziz, M.H. Isa, A.A. Zinatizadeh, Application of response surface methodology (RSM) to optimize coagulation-flocculation treatment of leachate using poly-aluminum chloride (PAC) and alum, J. Hazardous Mat. 163 (2009) 650-656.

[9] P. Casero. Puertollano IGCC power plant. Operacional experience and current developments, International Freiberg Conference on IGCC and XtL Technologies, Freiberg, Germany, May 2007.

[10] J. Fermoso, B. Arias, M.G. Plaza, C. Pevida, F. Rubiera, J.J. Pis, F. García-Peña, P. Casero, High-pressure co-gasification of coal with biomass and petroleum coke, Fuel Proc. Tech. 90 (2009) 926-932.

[11] R.O. Kuehl, Design of experiments: statistical principles of research design and analysis, second ed. Duxbury Thomson Learning, New York, 2000. 
[12] Y.J. Kim, S.H. Lee, S.D. Kim, Coal gasification characteristics in a downer reactor, Fuel, 80 (2001) 1915-1922.

[13] R. Xiao, M. Zhang, B. Jin, Y. Huang, High-temperature air/steam-blown gasification of coal in a pressurized spout-fluid bed, Energy \& Fuels, 20 (2006) 715-720.

[14] R. Xiao, M. Zhang, B. Jin, Y. Xiaong, H. Zhou, Y. Duan, Z. Zhong, X. Chen, Y. Huang, Air blown partial gasification of coal in a pilot plant pressurized spoutfluid bed reactor, Fuel, 86 (2007) 1631-1640.

[15] T.A. Sue-A-Quan, A.P. Watkinson, R.P. Gaikwad, C.J. Lim, B.R. Ferris, Steam gasification in a pressurized spouted bed reactor, Fuel Proc. Tech. 27 (1991) 6781.

[16] A. Ocampo, E. Arenas, F. Chejne, J. Espinel, C. Londoño, J. Aguirre, J.D. Perez, An experimental study on gasification of Colombian coal in fluidised bed, Fuel, 82 (2003) 161-164.

[17] F. Pinto, C. Franco, André R. Neto, C. Tavares, M. Dias, I. Gulyurtlu, I. Cabrita, Effect of experimental conditions on co-gasification of coal, biomass and plastic wastes with air/steam mixtures in a fluidized bed system, Fuel, 82 (2003) 19671976.

[18] J. Huang, Y. Fang, H. Chen, Y. Wang, Coal gasification characteristics in a pressurized fluidized bed, Energy \& Fuels, 17 (2003) 1474-1479.

[19] A. Kumar, K. Eskridge, D.D. Jones, M.A. Hanna, Steam-air fluidized bed gasification of distillers grains: Effects of steam to biomass ratio, equivalence ratio and gasification temperature, Biores. Tech. 100 (2009) 2062-2068.

[20] R. Govind, J. Shah, Modelling and simulation of an entrained flow coal gasifier, AIChE J. 30 (1984) 79-92. 
Table 1. Proximate and ultimate analyses and high heating value of the coal sample

\begin{tabular}{|c|c|c|c|c|c|c|c|c|}
\hline \multirow{2}{*}{ Sample } & \multicolumn{2}{|c|}{$\begin{array}{l}\text { Proximate Analysis } \\
\text { (wt. } \%, \mathrm{db})\end{array}$} & \multicolumn{5}{|c|}{ Ultimate Analysis (wt.\%, daf) } & \multirow{2}{*}{$\begin{array}{c}\mathrm{HHV} \\
\left(\mathrm{MJ} \mathrm{kg}^{-1} \text {, daf) }\right.\end{array}$} \\
\hline & Ash & V.M. & $\mathrm{C}$ & $\mathrm{H}$ & $\mathrm{N}$ & $\mathrm{S}$ & $\mathrm{O}^{*}$ & \\
\hline PT & 36.3 & 24.7 & 71.2 & 4.8 & 1.5 & 1.7 & 20.8 & 29.1 \\
\hline
\end{tabular}

dry basis (db); dry ash free basis (daf); ${ }^{*}$ calculated by difference 
Table 2. Experimental values of the response variables for the face centered central composite design

\begin{tabular}{|c|c|c|c|c|c|c|c|c|c|}
\hline \multirow{2}{*}{ Exp. $\mathrm{N}^{\mathrm{o}}$} & \multirow{2}{*}{$\begin{array}{c}\mathrm{T}\left({ }^{\mathrm{o}} \mathrm{C}\right) \\
\left(\mathrm{X}_{\mathrm{T}}\right)\end{array}$} & \multicolumn{2}{|c|}{$\mathrm{O}_{2}($ vol. $\%) \mathrm{H}_{2} \mathrm{O}$ (vol.\%) } & \multicolumn{6}{|c|}{ Response variables } \\
\hline & & $\left(\mathrm{Xo}_{2}\right)$ & $\left(\mathrm{X}_{\mathrm{H}_{2} \mathrm{O}}\right)$ & $\mathrm{H}_{2}$ & $\mathrm{CO}$ & $\mathrm{H}_{2}+\mathrm{CO}$ & $\mathrm{H}_{2} / \mathrm{CO}$ & $\eta$ & $X$ \\
\hline 1 & $900(-1)$ & $5(-1)$ & $25(-1)$ & 31.8 & 18.8 & 50.6 & 1.69 & 56.7 & 57.2 \\
\hline 2 & $900(-1)$ & $5(-1)$ & $55(+1)$ & 38.3 & 17.1 & 55.4 & 2.24 & 66.1 & 62.3 \\
\hline 3 & $900(-1)$ & $15(+1)$ & $25(-1)$ & 21.0 & 15.6 & 36.6 & 1.34 & 39.3 & 67.8 \\
\hline 4 & $900(-1)$ & $15(+1)$ & $55(+1)$ & 26.1 & 12.6 & 38.7 & 2.08 & 45.1 & 77.2 \\
\hline 5 & $1000(+1)$ & $5(-1)$ & $25(-1)$ & 43.8 & 36.4 & 80.2 & 1.20 & 83.9 & 78.9 \\
\hline 6 & $1000(+1)$ & $5(-1)$ & $55(+1)$ & 31.8 & 18.8 & 50.6 & 1.81 & 56.7 & 57.2 \\
\hline 7 & $1000(+1)$ & $15(+1)$ & $25(-1)$ & 34.2 & 29.6 & 63.8 & 1.15 & 66.0 & 88.6 \\
\hline 8 & $1000(+1)$ & $15(+1)$ & $55(+1)$ & 44.9 & 22.4 & 67.4 & 2.00 & 72.3 & 98.5 \\
\hline 9 & $900(-1)$ & $10(0)$ & $40(0)$ & 29.8 & 16.1 & 45.9 & 1.85 & 51.7 & 68.1 \\
\hline 10 & $1000(+1)$ & $10(0)$ & $40(0)$ & 45.0 & 30.8 & 75.8 & 1.46 & 80.6 & 88.8 \\
\hline 11 & $950(0)$ & $10(0)$ & $25(-1)$ & 28.2 & 23.6 & 51.8 & 1.25 & 52.7 & 66.5 \\
\hline 12 & $950(0)$ & $10(0)$ & $55(+1)$ & 37.0 & 19.5 & 56.5 & 1.91 & 60.9 & 74.2 \\
\hline 13 & $950(0)$ & $5(-1)$ & $40(0)$ & 40.1 & 23.7 & 63.8 & 1.72 & 69.1 & 64.3 \\
\hline 14 & $950(0)$ & $15(+1)$ & $40(0)$ & 27.4 & 17.9 & 45.4 & 1.58 & 48.0 & 75.8 \\
\hline 15 & $950(0)$ & $10(0)$ & $40(0)$ & 35.3 & 21.6 & 56.9 & 1.64 & 62.6 & 75.1 \\
\hline 16 & $950(0)$ & $10(0)$ & $40(0)$ & 37.9 & 23.6 & 61.5 & 1.61 & 67.5 & 81.1 \\
\hline 17 & $950(0)$ & $10(0)$ & $40(0)$ & 35.7 & 22.2 & 57.9 & 1.61 & 63.2 & 76.4 \\
\hline 18 & $950(0)$ & $10(0)$ & $40(0)$ & 39.0 & 22.9 & 61.9 & 1.70 & 67.3 & 80.4 \\
\hline 19 & $950(0)$ & $10(0)$ & $40(0)$ & 38.4 & 23.6 & 62.0 & 1.62 & 67.8 & 81.2 \\
\hline 20 & $950(0)$ & $10(0)$ & $40(0)$ & 36.4 & 21.9 & 58.3 & 1.66 & 642 & 76.3 \\
\hline
\end{tabular}


Table 3. Coded coefficients of quadratic models for the response variables $\left(\mathrm{H}_{2}, \mathrm{CO}\right.$ and $\left.\mathrm{H}_{2}+\mathrm{CO}\right)$, and the ANOVA evaluation of the models

\begin{tabular}{|c|c|c|c|c|c|c|c|c|c|c|c|c|}
\hline \multirow{2}{*}{$\begin{array}{l}\text { Response } \\
\text { variables }\end{array}$} & \multicolumn{4}{|c|}{$\mathrm{H}_{2}$} & \multicolumn{4}{|c|}{$\mathrm{CO}$} & \multicolumn{4}{|c|}{$\mathrm{H}_{2}+\mathrm{CO}$} \\
\hline & Coefficient & $\begin{array}{l}\text { Sum of } \\
\text { squares }\end{array}$ & DF & $\mathrm{p}$-value & Coefficient & $\begin{array}{l}\text { Sum of } \\
\text { squares }\end{array}$ & DF & p-value & Coefficient & $\begin{array}{c}\text { Sum of } \\
\text { squares }\end{array}$ & DF & p-value \\
\hline Intersection & 37.16 & 11687.11 & 1 & 0.000 & 22.85 & 4419.01 & 1 & 0.000 & 60.02 & 30482.77 & 1 & 0.000 \\
\hline$x_{T}$ & 7.83 & 613.09 & 1 & 0.000 & 7.07 & 499.85 & 1 & 0.000 & 14.92 & 2226.06 & 1 & 0.000 \\
\hline$x_{\mathrm{O}_{2}}$ & -5.78 & 334.08 & 1 & 0.000 & -2.96 & 87.62 & 1 & 0.000 & -8.73 & 762.13 & 1 & 0.000 \\
\hline$x_{\mathrm{H}_{2} \mathrm{O}}$ & 4.47 & 199.81 & 1 & 0.000 & -2.07 & 42.85 & 1 & 0.000 & 2.42 & 58.56 & 1 & 0.002 \\
\hline$x_{T}^{2}$ & 0.16 & 0.07 & 1 & 0.824 & 0.27 & 0.20 & 1 & 0.563 & 0.42 & 0.49 & 1 & 0.703 \\
\hline$x_{O_{2}}^{2}$ & 0.51 & 0.73 & 1 & 0.490 & -0.38 & 0.40 & 1 & 0.415 & 0.17 & 0.08 & 1 & 0.876 \\
\hline$x_{\mathrm{H}_{2} \mathrm{O}}^{2}$ & -0.64 & 1.11 & 1 & 0.396 & 0.37 & 0.37 & 1 & 0.431 & -0.28 & 0.21 & 1 & 0.802 \\
\hline$x_{T} x_{O_{2}}$ & 0.11 & 0.10 & 1 & 0.794 & -1.05 & 8.82 & 1 & 0.003 & -0.94 & 7.03 & 1 & 0.170 \\
\hline$x_{T} x_{\mathrm{H}_{2} \mathrm{O}}$ & 1.59 & 20.16 & 1 & 0.004 & -0.90 & 6.48 & 1 & 0.007 & 0.71 & 4.06 & 1 & 0.287 \\
\hline$x_{\mathrm{O}_{2}} x_{\mathrm{H}_{2} \mathrm{O}}$ & -0.54 & 2.31 & 1 & 0.231 & -0.48 & 1.81 & 1 & 0.103 & -1.01 & 8.20 & 1 & 0.142 \\
\hline$x_{T} x_{O_{2}} x_{H_{2} O}$ & -0.19 & 0.28 & 1 & 0.665 & -0.15 & 0.18 & 1 & 0.581 & -0.34 & 0.91 & 1 & 0.605 \\
\hline Model & & 1171.23 & 10 & 0.000 & & 648.50 & 10 & 0.000 & & 3067.84 & 10 & 0.000 \\
\hline Error & & 12.63 & 9 & & & 4.93 & 9 & & & 28.48 & 9 & \\
\hline Total & & 1183.87 & 19 & & & 653.43 & 19 & & & 3096.31 & 19 & \\
\hline Lack of fit & & 1.00 & 4 & 0.975 & & 1.20 & 4 & 0.801 & & 2.08 & 4 & 0.978 \\
\hline Pure error & & 11.63 & 5 & & & 3.73 & 5 & & & 26.40 & 5 & \\
\hline $\mathrm{R}^{2}$ & 0.989 & & & & 0.992 & & & & 0.991 & & & \\
\hline Adj - $R^{2}$ & 0.977 & & & & 0.984 & & & & 0.981 & & & \\
\hline
\end{tabular}


Table 4. Coded coefficients of quadratic models for the response variables $\left(\mathrm{H}_{2} / \mathrm{CO}, \eta\right.$ and $\left.\mathrm{X}\right)$, and the ANOVA evaluation of the models

\begin{tabular}{|c|c|c|c|c|c|c|c|c|c|c|c|c|}
\hline \multirow{2}{*}{$\begin{array}{l}\text { Response } \\
\text { variables }\end{array}$} & \multicolumn{4}{|c|}{$\mathrm{H}_{2} / \mathrm{CO}$} & \multicolumn{4}{|c|}{$\eta$} & \multicolumn{4}{|c|}{$X$} \\
\hline & Coefficient & $\begin{array}{l}\text { Sum of } \\
\text { squares }\end{array}$ & $\mathrm{DF}$ & p-value & Coefficient & $\begin{array}{l}\text { Sum of } \\
\text { squares }\end{array}$ & $\mathrm{DF}$ & p-value & Coefficient & $\begin{array}{l}\text { Sum of } \\
\text { squares }\end{array}$ & DF & p-value \\
\hline Intersection & 1.628 & 22.421 & 1 & 0.000 & 65.53 & 36332.35 & 1 & 0.000 & 78.33 & 51916.52 & 1 & 0.000 \\
\hline$x_{T}$ & -0.158 & 0.250 & 1 & 0.000 & 14.24 & 2027.78 & 1 & 0.000 & 11.26 & 1267.88 & 1 & 0.000 \\
\hline$x_{O_{2}}$ & -0.051 & 0.026 & 1 & 0.003 & -10.36 & 1073.30 & 1 & 0.000 & 5.48 & 300.30 & 1 & 0.000 \\
\hline$x_{\mathrm{H}_{2} \mathrm{O}}$ & 0.341 & 1.163 & 1 & 0.000 & 4.43 & 196.25 & 1 & 0.000 & 4.36 & 190.10 & 1 & 0.000 \\
\hline$x_{T}^{2}$ & 0.045 & 0.006 & 1 & 0.087 & 0.48 & 0.64 & 1 & 0.664 & 0.25 & 0.172 & 1 & 0.851 \\
\hline$x_{O_{2}}^{2}$ & 0.040 & 0.005 & 1 & 0.122 & 0.88 & 2.14 & 1 & 0.433 & -0.65 & 1.16 & 1 & 0.628 \\
\hline$x_{\mathrm{H}_{2} \mathrm{O}}^{2}$ & -0.030 & 0.002 & 1 & 0.244 & -0.87 & 2.07 & 1 & 0.440 & -0.35 & 0.34 & 1 & 0.793 \\
\hline$x_{T} x_{O_{2}}$ & 0.081 & 0.053 & 1 & 0.000 & -0.71 & 4.06 & 1 & 0.287 & -0.96 & 7.41 & 1 & 0.237 \\
\hline$x_{T} x_{H_{2} O}$ & 0.021 & 0.004 & 1 & 0.160 & 0.71 & 4.06 & 1 & 0.287 & 0.86 & 5.95 & 1 & 0.285 \\
\hline$x_{\mathrm{O}_{2}} x_{\mathrm{H}_{2} \mathrm{O}}$ & 0.054 & 0.023 & 1 & 0.004 & -1.49 & 17.70 & 1 & 0.042 & 0.34 & 0.91 & 1 & 0.667 \\
\hline$x_{T} x_{O_{2}} x_{H_{2} O}$ & 0.006 & 0.000 & 1 & 0.663 & -0.59 & 2.76 & 1 & 0.375 & -0.74 & 4.35 & 1 & 0.357 \\
\hline Model & & 1.537 & 10 & 0.000 & & 3330.17 & 10 & 0.000 & & 1779.80 & 10 & 0.000 \\
\hline Error & & 0.014 & 9 & & & 28.55 & 9 & & & 41.49 & 9 & \\
\hline Total & & 1.551 & 19 & & & 3358.72 & 19 & & & 1821.29 & 19 & \\
\hline Lack of fit & & 0.008 & 4 & 0.317 & & 0.65 & 4 & 0.998 & & 3.06 & 4 & 0.978 \\
\hline Pure error & & 0.006 & 5 & & & 27.89 & 5 & & & 38.43 & 5 & \\
\hline $\mathrm{R}^{2}$ & 0.991 & & & & 0.992 & & & & 0.977 & & & \\
\hline Adj $-R^{2}$ & 0.981 & & & & 0.982 & & & & 0.952 & & & \\
\hline
\end{tabular}


Table 5. Polynomial models for the response variables as a function of the decoded operation variables ( $\mathrm{T}$ is the temperature in ${ }^{\circ} \mathrm{C}$; $\mathrm{O}_{2}$ is the oxygen concentration in vol.\%; and $\mathrm{H}_{2} \mathrm{O}$ is the steam concentration in vol.\%)

\begin{tabular}{|c|c|}
\hline Response & $2^{\text {nd }}$ order polynomial equations \\
\hline $\mathrm{H}_{2}$ & $-31.512+0.072 \cdot \mathrm{T}-1.156 \cdot \mathrm{O}_{2}-1.713 \cdot \mathrm{H}_{2} \mathrm{O}+0.002 \cdot \mathrm{T} \cdot \mathrm{H}_{2} \mathrm{O}$ \\
\hline $\mathrm{CO}$ & $-185.41+0.231 \cdot \mathrm{T}+3.398 \cdot \mathrm{O}_{2}+1.002 \cdot \mathrm{H}_{2} \mathrm{O}-0.004 \cdot \mathrm{T} \cdot \mathrm{O}_{2}-0.001 \cdot \mathrm{T} \cdot \mathrm{H}_{2} \mathrm{O}$ \\
\hline $\mathrm{H}_{2}+\mathrm{CO}$ & $-212.293+0.298 \cdot \mathrm{T}-1.746 \cdot \mathrm{O}_{2}+0.161 \cdot \mathrm{H}_{2} \mathrm{O}$ \\
\hline $\mathrm{H}_{2} / \mathrm{CO}$ & $7.2248-0.0064 \cdot \mathrm{T}-0.3476 \cdot \mathrm{O}_{2}+0.0156 \cdot \mathrm{H}_{2} \mathrm{O}+0.0003 \cdot \mathrm{T} \cdot \mathrm{O}_{2}+0.0007 \cdot \mathrm{O}_{2} \cdot \mathrm{H}_{2} \mathrm{O}$ \\
\hline$\eta$ & $-203.812+0.285 \cdot \mathrm{T}-1.279 \cdot \mathrm{O}_{2}+0.494 \cdot \mathrm{H}_{2} \mathrm{O}-0.02 \cdot \mathrm{O}_{2} \cdot \mathrm{H}_{2} \mathrm{O}$ \\
\hline$X$ & $-158.572+0.225 \cdot \mathrm{T}+1.096 \cdot \mathrm{O}_{2}+0.291 \cdot \mathrm{H}_{2} \mathrm{O}$ \\
\hline
\end{tabular}



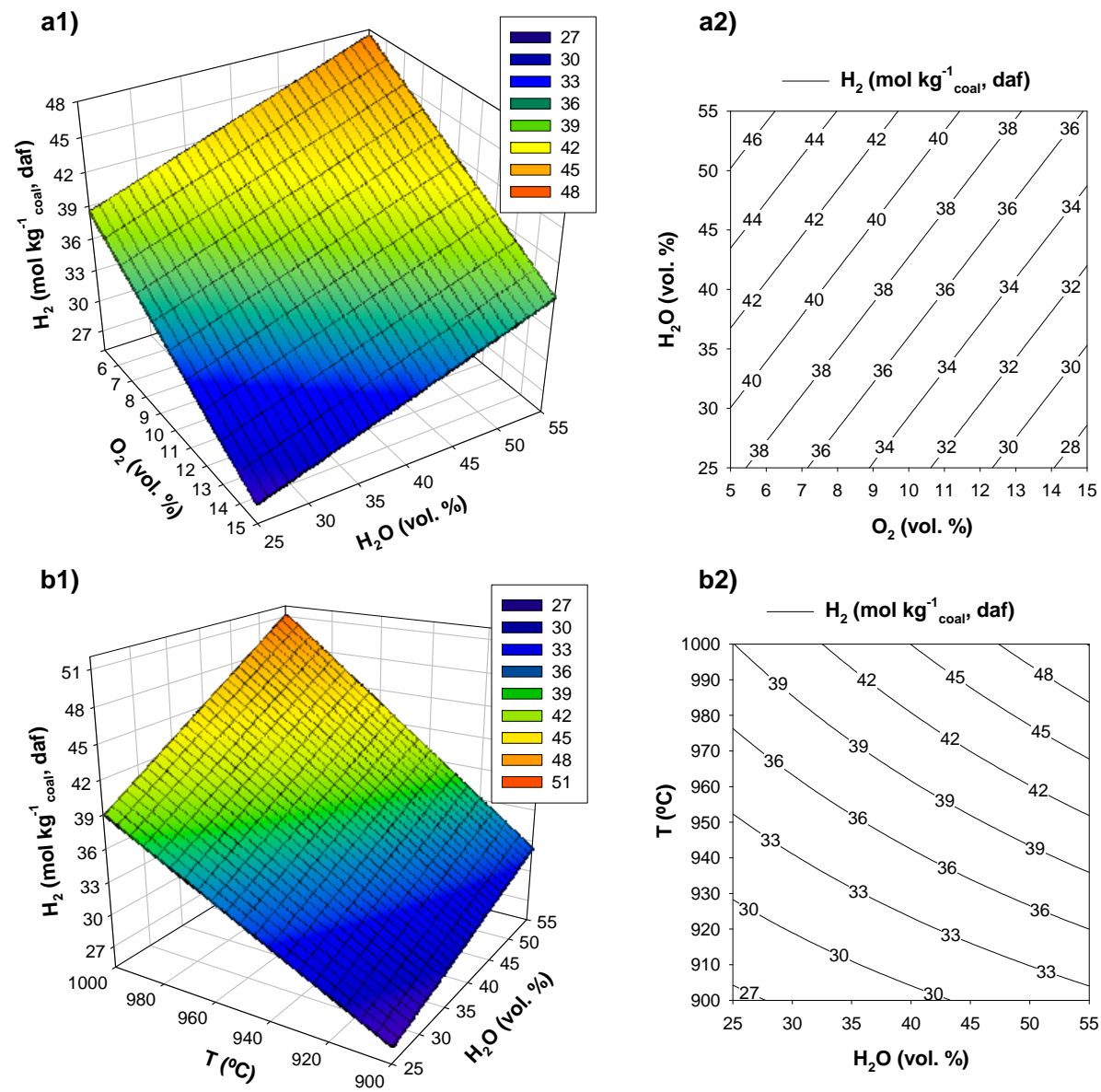

Figure 1. Response surface (1) and contour plots (2) representing the combined effect of oxygen and steam concentration (a), and the combined effect of temperature and steam concentration (b) on $\mathrm{H}_{2}$ production, with the temperature and the oxygen concentration set at $950{ }^{\circ} \mathrm{C}$ and 10 vol.\%, respectively. 
a1)

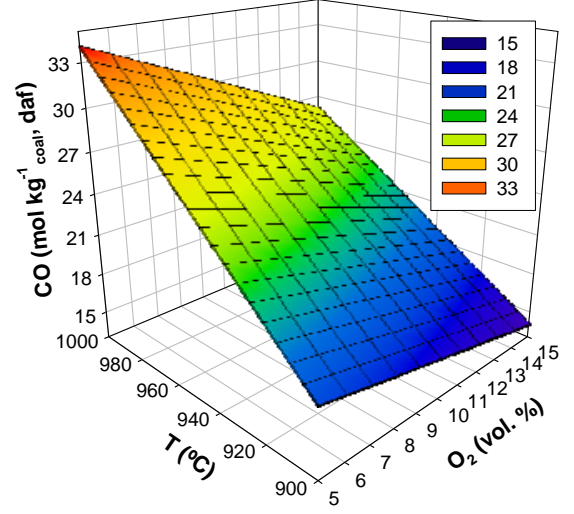

b1)

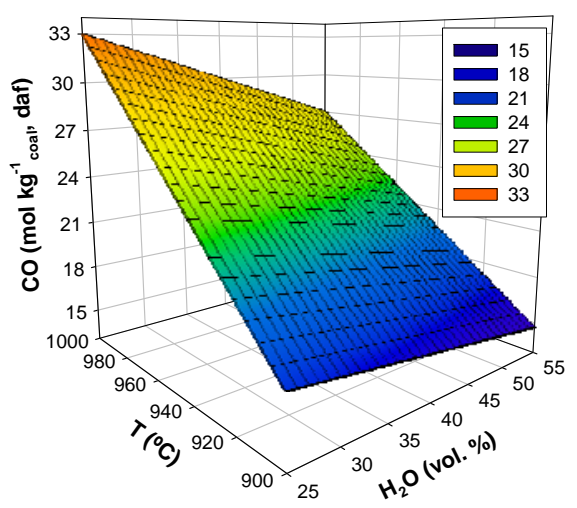

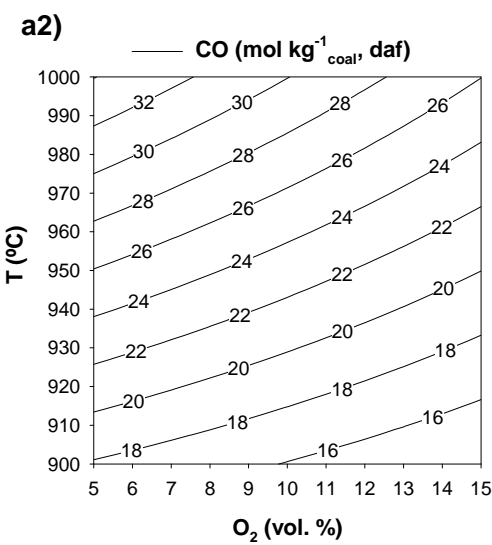

b2)

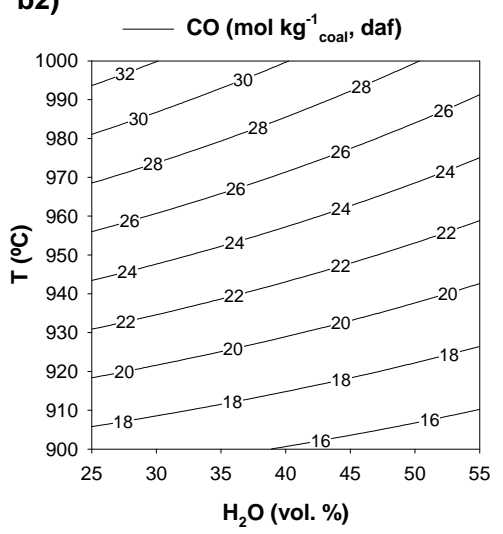

Figure 2. Response surface (1) and contour plots (2) representing the combined effect of temperature and oxygen concentration (a), and the combined effect of temperature and steam concentration (b) on CO production, with the steam and the oxygen concentration set at 5 and 10 vol. \%, respectively. 
a1)

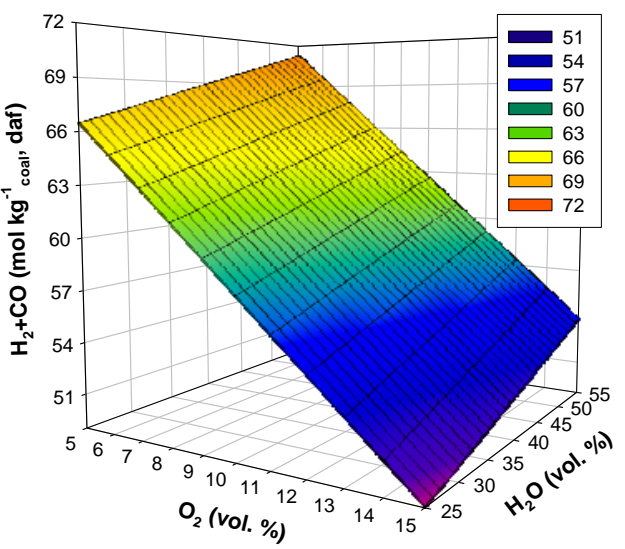

b1)

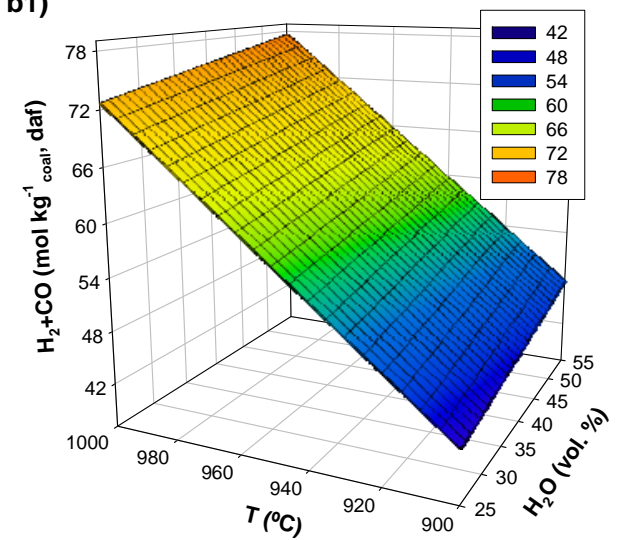

a2)

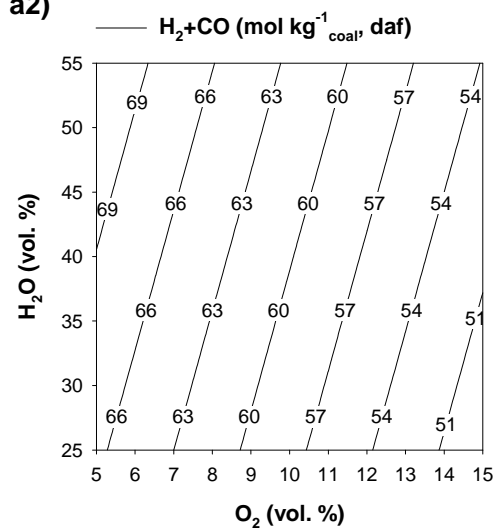

b2)

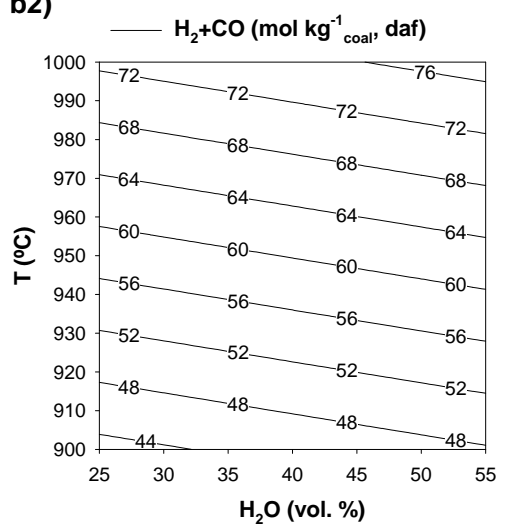

Figure 3. Response surface (1) and contour plots (2) representing the combined effect of oxygen and steam concentration (a), and the combined effect of temperature and steam concentration (b) on $\left(\mathrm{H}_{2}+\mathrm{CO}\right)$ production, with the temperature and the oxygen concentration set at $950^{\circ} \mathrm{C}$ and 10 vol. $\%$, respectively. 
a)

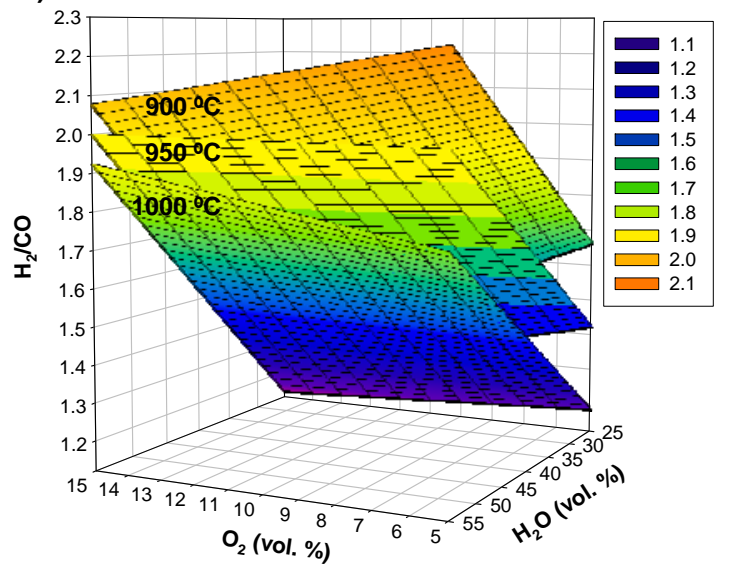

b2)

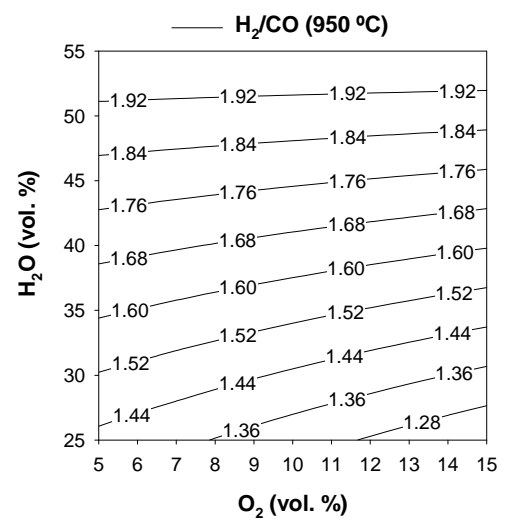

b1)

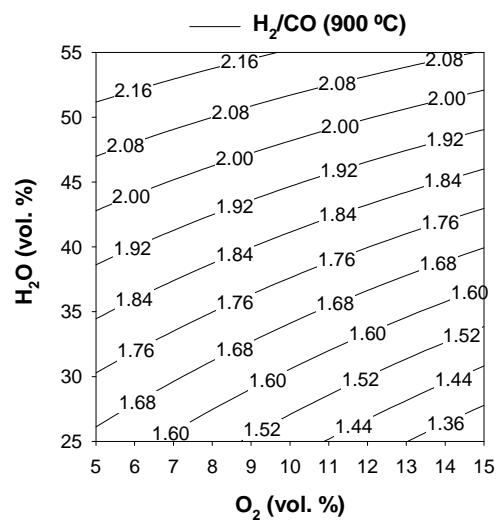

b3)

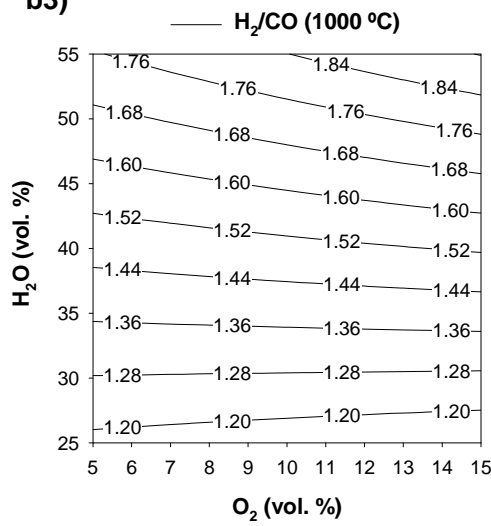

Figure 4. Response surfaces (a) and contour plots (b) for the $\mathrm{H}_{2} / \mathrm{CO}$ ratio, with the temperature set at three levels 900,950 and $1000{ }^{\circ} \mathrm{C}$. 
a)

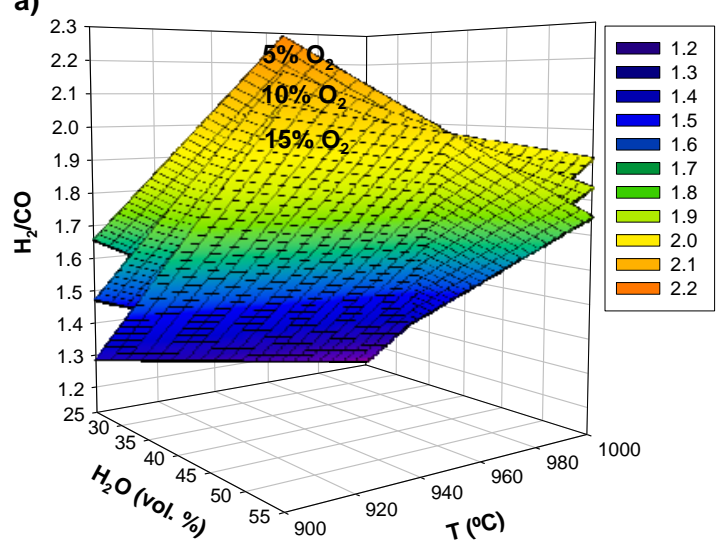

b2)

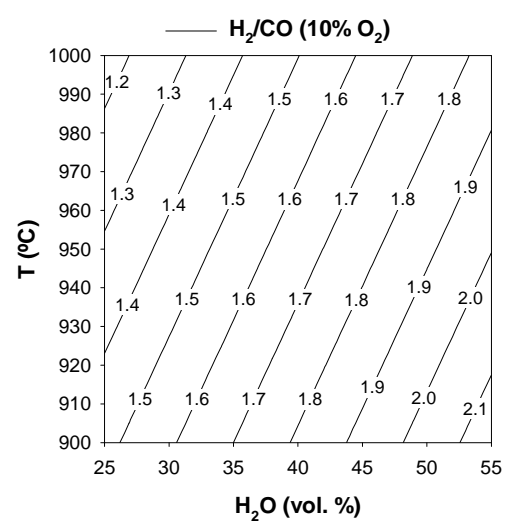

b1)

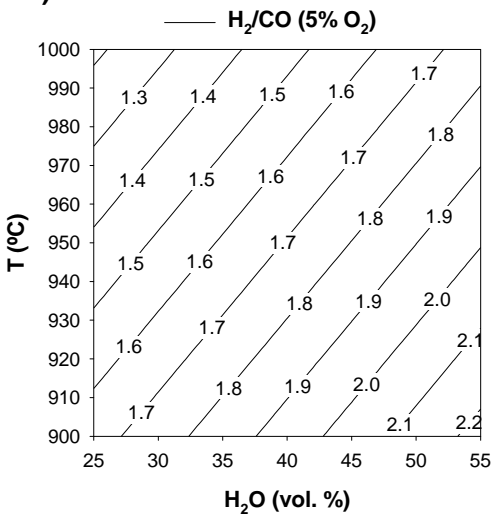

b3)

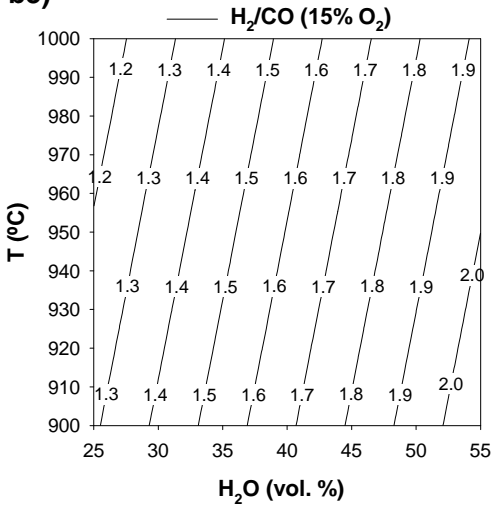

Figure 5. Response surfaces (a) and contour plots (b) for the $\mathrm{H}_{2} / \mathrm{CO}$ ratio, with the oxygen concentration set at three levels 5, 10 and 15 vol.\%. 
a)

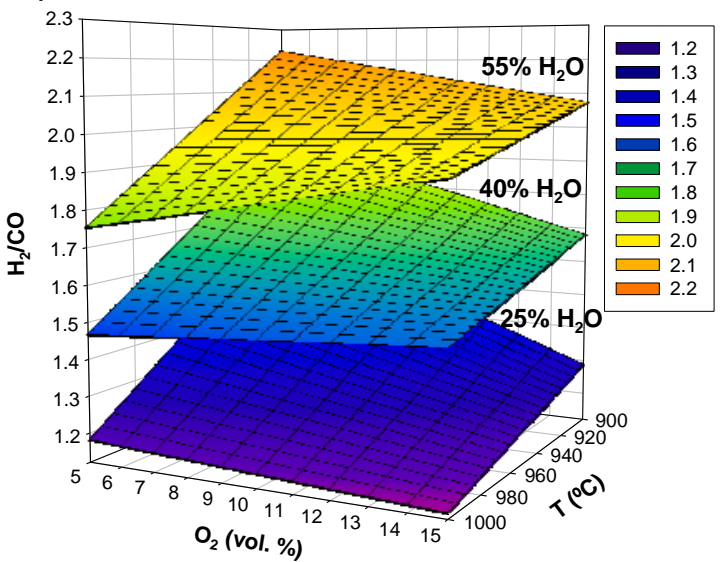

b2)

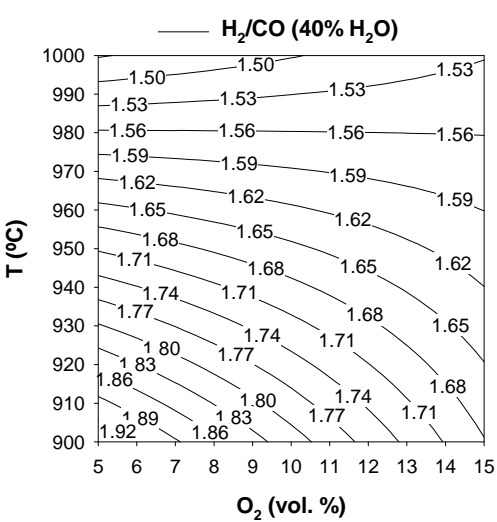

b1)

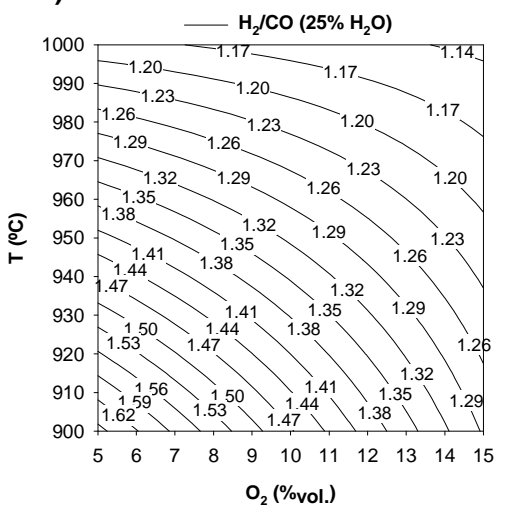

b3)

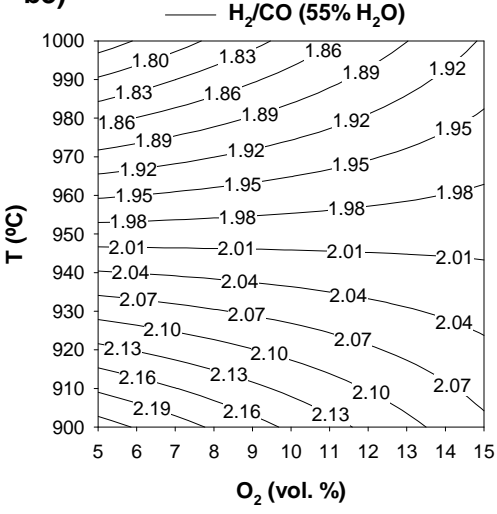

Figure 6. Response surfaces (a) and contour plots (b) for the $\mathrm{H}_{2} / \mathrm{CO}$ ratio, with the steam concentration set at three levels 25,40 and 55 vol.\%. 
a1)

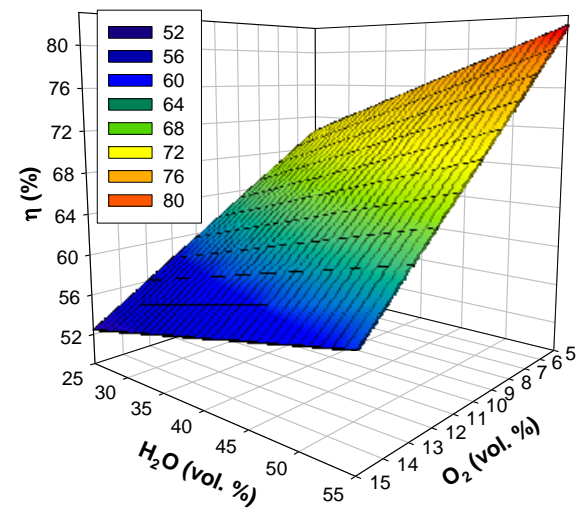

b1)

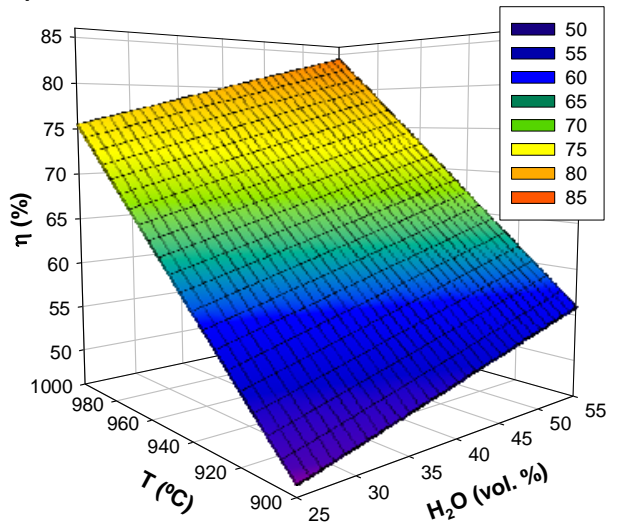

a2)

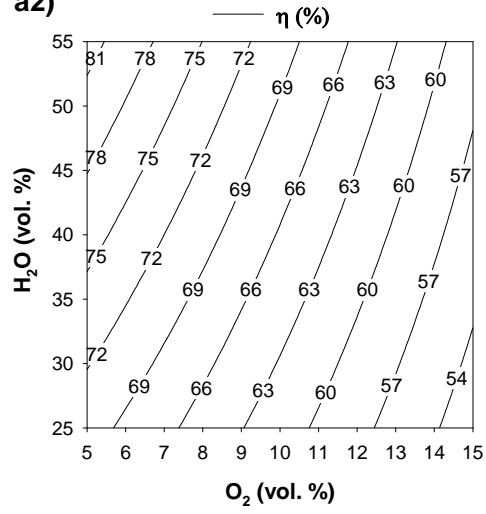

b2)

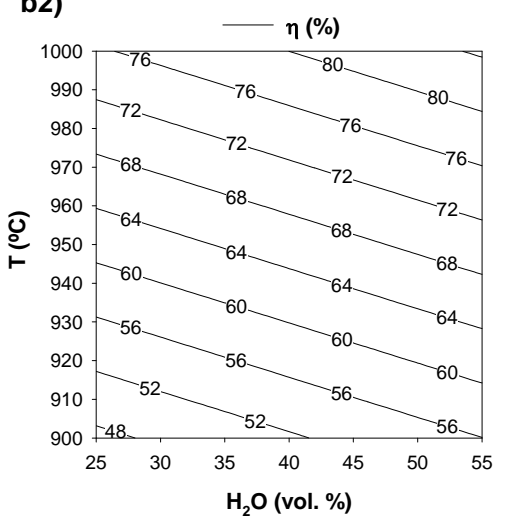

Figure 7. Response surface (1) and contour plots (2) representing the combined effect of oxygen and steam concentration (a), and the combined effect of temperature and steam concentration (b) on cold gas efficiency $(\eta)$, with the temperature and the oxygen concentration set at $950{ }^{\circ} \mathrm{C}$ and 10 vol.\%, respectively. 

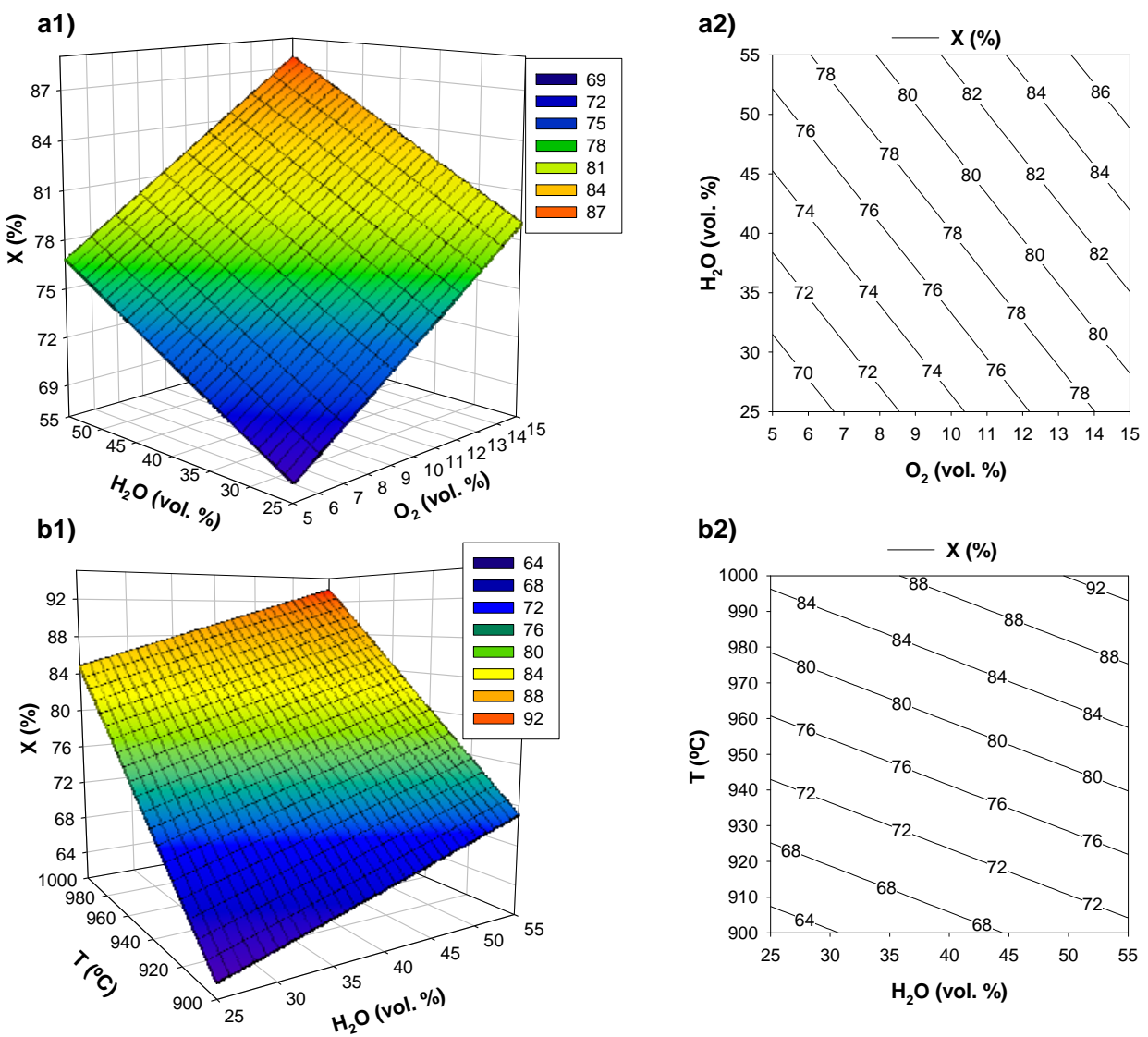

Figure 8. Response surface (1) and contour plots (2) representing the combined effect of oxygen and steam concentration (a), and the combined effect of temperature and steam concentration (b) on carbon conversion $(X)$, with the temperature and the oxygen concentration set at $950{ }^{\circ} \mathrm{C}$ and 10 vol.\%, respectively. 

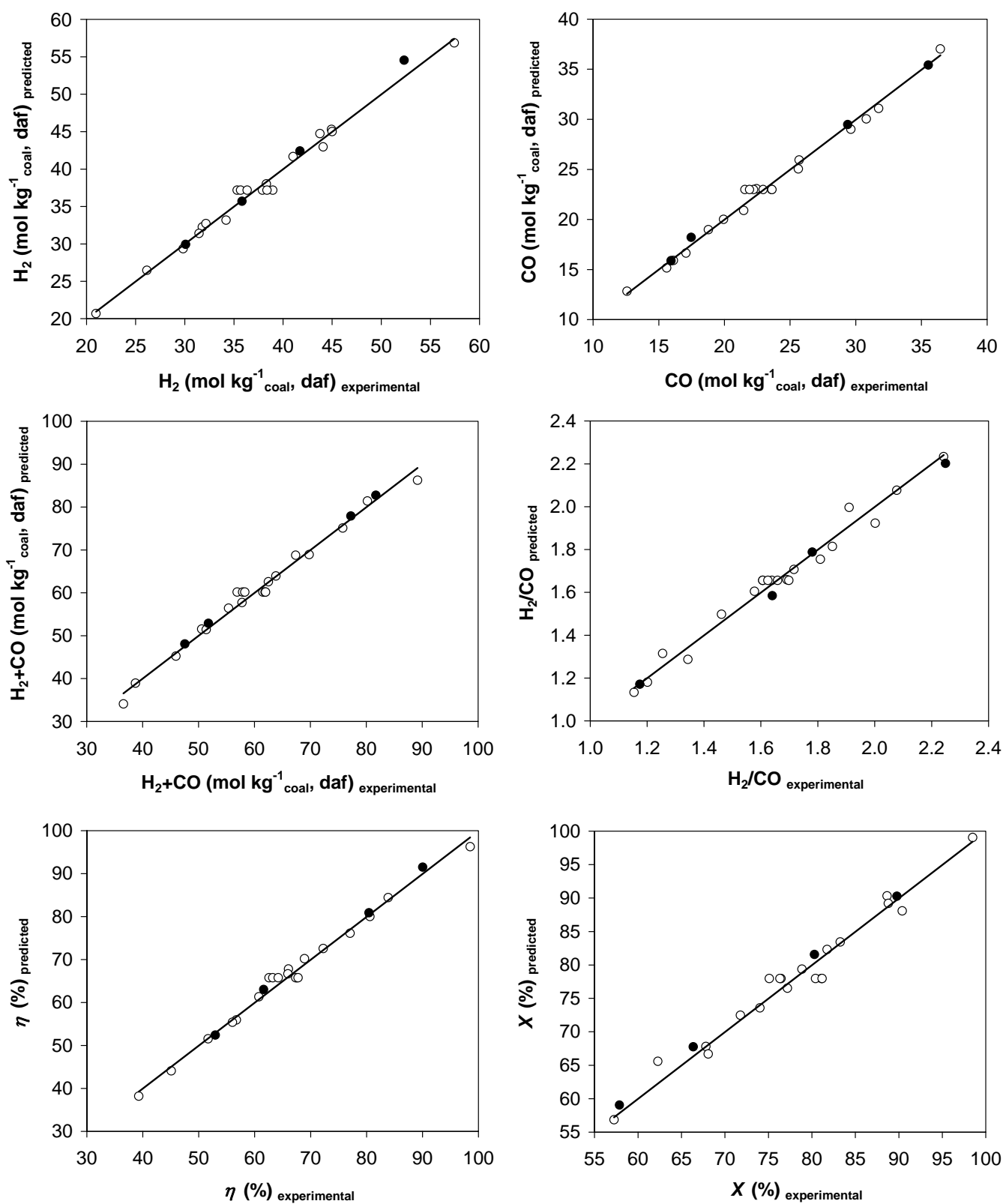

Figure 9. Theoretical values of the response variables predicted from the respective models versus the experimental values. (o): Experiments used for the calculations of the models. (๑): Additional experiments not forming part of the experimental design. 